\title{
Designs of devices: The vacuum aspirator and American abortion technology
}

\section{Tanfer Emin Tunc}

Department of American Culture and Literature. Hacettepe University, Ankara. tanfer@hacettepe.edu.tr

Dynamis

[0211-9536] 2008; 28: 353-376
Fecha de recepción: 5 de marzo de 2007

Fecha de aceptación: 16 de enero de 2008

SUMARIO: 1.-Introduction. 2.-The origins of vacuum aspiration. 3.-From «regulating the menses» to vacuum suction abortion 4.-Vacuum aspiration enters American abortion therapeutics. 5.-American physicians' reactions to vacuum aspiration. 6.-Technological innovation, legalization, and the rise of vacuum suction abortion. 7.- The Karman cannula and the politics of abortion technology. 8.-Conclusion: The Karman revolution.

ABSTRACT: In 1965, 71\% of legal abortions in the United States were performed using the surgical procedure of dilation and curettage. By 1972, a mere seven years later, approximately the same percentage (72.6\%) of legal abortions in the United States were performed using a completely new abortion technology: the electrical vacuum aspirator. This article examines why, in less than a decade, electric vacuum suction became American physicians' abortion technology of choice. It focuses on factors such as political and professional feasibility (the technology was able to complement the decriminalization of abortion in the US, and the interests, abilities, commitments, and personal beliefs of physicians); clinical compatibility (it met physician/patient criteria such as safety, simplicity and effectiveness); and economic viability (it was able to adapt to market factors such as production, cost, supply/demand, availability, and distribution).

PALABRAS CLAVE: Aborto por succión, aspirador de vacio, tecnologías abortivas, interrupción del embarazo, re-configuración de tecnologías.

KEYWORDS: Vacuum suction abortion, vacuum aspirator, abortion technologies, pregnancy termination, technological reconfiguration. 


\section{Introduction}

In 1965, 71 percent of legal abortions in the United States were performed using the surgical procedure of dilation and curettage (D\&C) ${ }^{1}$. By 1972, a mere seven years later, approximately the same percentage, 72.6 percent, of legal abortions in the United States were performed using a completely new abortion technology: the electrical vacuum aspirator ${ }^{2}$. This new machine completely revolutionized the way early, or first trimester, abortions were performed, and are still being performed, around the world. It virtually eliminated some of the risks associated with the traditional $D \& C$, such as infection and uterine perforation, provided $\mathrm{D} \& \mathrm{C}$ opponents with a safe and feasible political and technological alternative, and eventually became one of the most frequently used medical technologies in the United States ${ }^{3}$.

Even though the transition to electrical vacuum aspiration occurred over a relatively short period of time, the technology initially encountered resistance from some US physicians. According to Joel Howell, such a reaction is typical in professions such as medicine where a natural conservatism produces a tendency towards technological stasis. As Howell notes, this stasis can be ascribed to the rigors of professional training: once having been trained to use a particular set of instruments in a particular technical system, and once having become proficient at their craft, most professionals are reluctant to change, especially when the profession deals, as medicine does, with life or death situations ${ }^{4}$. In the case of electrical vacuum aspiration, physician-skepticism was well-founded: the early equipment was unreliable, impractical, and was not technologically compatible with the American therapeutic abortion system. Moreover, many physicians did not feel comfortable abandoning the traditional $D \& C$ for an inconvenient and potentially dangerous apparatus. However, professional attitudes regarding the new technology began to change when respected activist-physicians such

\footnotetext{
1. Tietze, Christopher. Therapeutic abortions in the United States. American Journal of Obstetrics and Gynecology. 1968; 101 (6): 784-787.

2. Van der Vlugt, Theresa et al. Uterine aspiration techniques. Population report, Series F. 1973; 3: F-26.

3. Hodgson, Jane E. Abortion and sterilization: medical and social aspects. London: Academic Press; 1981, p. 236.

4. Howell, Joel D. Technology in the hospital. Baltimore: Johns Hopkins University Press; 1996, p. 16-17.
} 
as Bernard Nathanson, Robert Hall and Alan Guttmacher began to advocate an immediate shift from the $D \& C$ to electrical vacuum aspiration.

The transition to electrical vacuum aspiration was also catalyzed by what Stuart Blume has called a social, economic, or political «crisis» ${ }^{5}$. This came in the form of the 1973 Roe v. Wade Supreme Court decision, which decriminalized abortion in the United States, dismantled the therapeutic abortion system, and placed pregnancy termination firmly in the hands of obstetrician/gynecologists. Legalized pregnancy termination inspired many physicians to try new abortion technologies, such as the Karman cannula, which won converts to electrical vacuum aspiration by making it a great deal cheaper and safer. Thus, this critical juncture not only facilitated the diffusion of electrical vacuum suction, but also reinforced the authority of specialized professionals as the sole purveyors of pregnancy termination, and its techniques.

What is most fascinating about this technological transition is that these abortion pioneers not only encouraged technological change, but also technological innovation. Many of the same American physicians who supported the electrical vacuum suction technique soon found themselves functioning as innovators, who, in partnership with local entrepreneurs, engaged in the process of technological reconfiguration -improving and adapting the suction apparatus to fit their clinical situations - thus illustrating Wiebe Bijker's contention that technologies not only shape society, but are also shaped by them (i.e., are socially-constructed) ${ }^{6}$. They became technological agents who solved engineering problems through «incremental rather than radical means, seldom depending on the results of long-term research in the basic sciences, and generally employing entrepreneurial skills rather than fundamentally new knowledge» ${ }^{7}$. The technologies they created embodied compromise, negotiation and closure. They were reflections of their social and medical contexts, and «mirrored trade-offs with society. Politics, economics, professional preferences, prejudices and skills, design

5. Blume, Stuart. Insight and industry. Cambridge, MA: MIT Press; 1992, p. 5-8; Hiddinga, Anja. Changing normality: Pregnancy and scientific knowledge claims. Amsterdam: University of Amsterdam; 1995.

6. Bijker, Wiebe, ed. Shaping Technology/Building Society. Cambridge, MA: MIT Press; 1992, p. 3; Grint, Keith; Woolgar, Steve. The machine at work: Technology, work and organization. Cambridge, MA: Polity Press; 1997.

7. Ekelman, Karen B., ed. New medical devices. Washington, D.C.: National Academy Press; 1988, p. v. 
tools, available raw materials, [were] all thrown into the melting pot whenever an [instrument] was designed and built» ${ }^{8}$. Thus, the electric vacuum suction technique triumphed because it was politically and professionally feasible (i.e., it was able to complement the decriminalization of abortion in the US, as well as the interests, abilities, commitments, and personal beliefs of physicians); clinically compatible (i.e., it met physician/patient criteria such as safety, simplicity, and effectiveness); and economically viable (i.e., able to adapt to market factors such as production, cost, supply/demand, availability, and distribution).

\section{The origins of vacuum aspiration}

Despite the fact that suction has long been a part of medical therapeutics, very little evidence exists linking aspiration to fertility control before the mid 1800s. In 1849, American physician Frederick Hollick made the first association between dry cupping, or the process through which alcohol is burned in a vessel and placed against the skin in order to form a vacuum, and «regulating the menses». In his treatise Diseases of women, Hollick described «a Dr. Sunot's device»: an «airtight cup» designed to be used on the «lower parts» to restore menstruation. According to Hollick, this device was «one of the most powerful and certain means of bringing on the menstrual flow» ${ }^{9}$. In fact, Hollick claimed that this machine was so powerful that it could pull blood right through the pores of the skin, and warned that it should not be used irresponsibly ${ }^{10}$.

The Scottish physician, Sir James Young Simpson, made the next association between negative vacuum pressure and the induction of delayed menstruation. In 1863, the same year he helped popularize anesthesia by administering chloroform to Queen Victoria during childbirth, he described a number of «techniques for the restoration of [menstrual] function». Simpson conveyed how his fascination with Hollick's dry cupping led him to develop the «exhausting syringe», an apparatus which made use of a thin metal tube, or catheter, and manual vacuum suction to induce menstruation: «I have made frequent use of a tube (...) [and] an exhausting syringe...

\footnotetext{
8. Bijker, n. 6, p. 3.

9. Hollick, Frederick. Diseases of women. New York: Stringer and Townsend; 1850, p. 157-158.

10. Mohr, James. Abortion in America. New York: Oxford University Press; 1978, p. 66.
} 
[through] which air could be withdrawn after it had been introduced into the cavity of the uterus (...). After a few strokes of the piston of the syringe (...) a small quantity of blood is found in the tube of the instrument after its withdrawal» ${ }^{11}$. Even though Hollick and Simpson relied on manual devices to extract matter, specifically blood, from the uterus, and did not directly suggest using the technique to induce abortion, it is very possible that they designed the apparatuses with pregnancy termination in mind, for as historian Susan Klepp has illustrated, during the eighteenth and nineteenth centuries, restoring or «bringing on the menses» was usually a euphemism for inducing abortion ${ }^{12}$.

Soon after Simpson published his lectures, physicians on both sides of the Atlantic began using syringes and hand-powered aspirators to treat gynecological ailments, specifically those involving the uterus. One of the first American physicians to follow Simpson's lead was T. Gaillard Thomas, who suggested Simpson's exhausting syringe, especially for the «diagnosis of the [pathological] states with which the gynecologist is called to deal». In 1876, Thomas described his own aspiration procedure, which entailed inserting very long, slender metal needles into the uterus. The needles were then connected to a powerful piston and a glass collection cylinder. He created a vacuum by drawing the piston upwards. This action forced the contents of the tumor, or whatever else he wanted to remove, through the needle, and into the collecting jar. The positive results Thomas obtained with this apparatus (which included a dramatically low incidence of uterine perforation) led him to recommend the aspirator for both diagnostic and therapeutic procedures ${ }^{13}$.

For those physicians who could not fashion their own aspirating syringe or manual vacuum suction unit, Thomas recommended Dieulafoy's apparatus, which by the late 1870 s could be purchased from a medical supplies manufacturer. In fact, trade manuals from the late nineteenth and early twentieth centuries, such as those printed by the W. F. Ford Surgical

11. Simpson, James Y. Clinical lectures on the diseases of women. Philadelphia: Blanchard and Lea; 1863; Simpson; James Y. Clinical lectures on the diseases of women. New York: D. Appleton and Co.; 1872, p. 635-637.

12. Klepp, Susan. Lost, hidden, obstructed, and repressed: Contraceptive and abortive technology in the early Delaware Valley. In: McGraw, Judith, ed. Early American technology. Chapel Hill: University of North Carolina Press; 1994, p. 68-113.

13. Thomas, T. Gaillard. A practical treatise on the diseases of women. Philadelphia: Henry C. Lea; 1876, p. 83-84. 
Instrument Company, and George Tiemann and Company of New York, typically showcased dozens of aspiration units and syringes specifically designed for gynecological purposes ${ }^{14}$. Companies, such as the KnyScheerer Corporation of America, provided physicians with «instruments of superior quality» as well as choice: it offered its patrons vacuum cups of all sizes, hand-powered syringes, aspirators, and multiple sized needles. It also sold larger manual vacuum suction devices, such Collin's, Dieulafoy's and Potain's apparatuses, all of which came with tubing and glass collecting jars with stopcocks ${ }^{15}$.

\section{From «regulating the menses» to vacuum suction abortion}

Thus by the turn of the twentieth century, US physicians could obtain and use manual aspiration devices for diagnostic and therapeutic purposes with relative ease. However, up to this point, American physicians were only employing the apparatuses to diagnose/treat uterine pathologies, and cases of «menstrual cessation» or amenorrhea, and «painful menstruation» or dysmenorrhea (the latter two conditions only suggested the possibility of pregnancy termination). The first individual in the international medical literature to admit using vacuum suction to induce abortion was Russian physician S. G. Bykov ${ }^{16}$. In the mid 1920s, he developed a simple, inexpensive, manual syringe which irritated the mucosal lining of the uterus and induced menstruation (i.e., abortion) in women who were in the early stages, or first few weeks, of pregnancy. His apparatus was basically a narrow, hollow, cone-shaped metal tube, attached to the end of a 100$200 \mathrm{cc}$ metal syringe. By «pulling the plunger of the syringe, he created a suction, or negative pressure, of $400 \mathrm{~mm} \mathrm{Hg}$, which irritated the mucosal lining of the uterus, and in a few days, induced [abortion]» (i.e., «normal menstruation»). The procedure took less than ten minutes, and he did not

14. W.F. Ford Surgical Instrument Company. Illustrated catalogue of surgical instruments and appliances. New York: W.F. Ford Surgical Instrument Company; 1893; George Tiemann and Company. The American armamentarium chirurgicum. New York: George Tiemann and Company; 1889.

15. Kny-Scheerer Corporation of America. Medical and surgical instrument catalogue. New York: Kny-Scheerer Corporation of America; 1924, p. 1147, 2325.

16. Bykov, S. G. Vrachebnoe Delo. 1927; 9: 21; Bykov, S. G. K voprosu o rasprostranenii protivozachatochnykh sredstv $\vee$ naselenii. Kazanskij meditsinskij zhurnal. 1928; 8: 760. 
encounter any complications in the twenty-five women he treated using this method. Bykov also mentioned that if used five to seven days prior to the predicted start of menstruation, his technique could help «regulate fertility». Moreover, he maintained that it was so safe that women could use the apparatus repeatedly and not suffer any negative side effects ${ }^{17}$.

Even though Bykov's work did little to incorporate the simultaneous scraping, or curetting, of the uterus, which would be an essential component of the modern vacuum aspirator, he did introduce the concept of using vacuum suction to terminate pregnancy. However, initially, his apparatus did not inspire further research on vacuum aspiration and pregnancy termination. Rather, it encouraged American physicians to continue using vacuum suction to treat pathologic gynecological conditions such as endometriosis which, given the criminality of abortion in the United States, was perhaps a safer choice ${ }^{18}$. In fact, it was during his extensive studies of the human endometrium during the early 1930s that John Rock, the devout Catholic Boston physician who was later involved in the development of the birth control pill, introduced the concept of the «sharp» vacuum curette.

Initially, Rock, like Simpson, Thomas and Bykov, found that by attaching a metal cannula, or narrow tube, to the end of a manual syringe, he could aspirate the uterine contents without discomfort to the patient. However, in 1933, one of his medical students suggested replacing the cannula with a wider, hollow, sharp curette, which would not only extract material from the uterus, but would also serve as a «cutting edge» during a biopsy or endometrial scraping ${ }^{19}$. Although Rock's wider vacuum curette required expanding the cervix using Hegar dilators, his work resulted in the creation of a new surgical technique: diagnostic vacuum curettage ${ }^{20}$. It also inspired Dr. Bela Lorinez of Hungary to design the first motorized, electric vacuum

17. Davis, Geoffrey. Interception of pregnancy. London: Angus and Robertson Publishers; 1974, p. 135-136; Van der Vlugt, Theresa et al. Menstrual regulation — what is it? Population Report, Series F. 1973; 2: F-9-F-23.

18. Klinger, H. H. Suction in obtaining endometrial biopsies. Journal of the American Medical Association. 1932; 99: 559.

19. Rock, John. The story of endometrial dating. American Journal of Obstetrics and Gynecology. 1973; 116 (1): 129-130; Van der Vlugt et al., n. 2, p. F-26.

20. Potts, Malcolm et al. Abortion. New York: Cambridge University Press; 1977, p. 184. 
pump in 1934, to which he attached his own «suction curette», which resembled a narrow metal Sims curette, with a hollowed-out handle ${ }^{21}$.

In 1935, Baltimore physician Emil Novak deftly combined Rock's specialized sharp curette (to which Novak added serrations) with Lorinez's electrical pump to create the first «modern» electric vacuum aspiration apparatus. He called the apparatus the "endometrial suction-curet», and suggested that it be used to test for ovulation by extracting secretory endometrium from inside the uterus. While Novak did take credit for the serrated edge, he praised Lorinez for his breakthrough, stating that he found «electric motor suction (...) preferable to [manual] syringes», and chose to work with the device because it could «curette a uterus very thoroughly». ${ }^{22}$

While suction curettes of this type became known as «Novaks», and to this day are used for endometrial biopsies, some resourceful physicians dared to use hospital Novak units to treat the incomplete abortions that were appearing in their emergency rooms. In fact, in the late 1930s, King's County Hospital in Brooklyn, New York equipped its emergency room with a permanent wall-mounted suction unit to manage incomplete abortions, which, under typical circumstances, would have been treated by dilation and curettage. Attending physicians often gave interns the task of treating incomplete abortions with electric vacuum aspiration. The patient would usually return home without hospitalization, which was rarely the case with therapeutic D\&Cs ${ }^{23}$.

Insofar as one can tell from the published literature, until the late 1950s, electrical vacuum suction was restricted mostly to endometrial biopsies, and a limited number of incomplete abortions. Moreover, it was not particularly widespread, perhaps because of the danger of the new technique (the vacuum had not yet been finely tuned, and too much suction was a frequent problem), the illegality of abortion in the US, and the precarious position of therapeutic abortions. However, it is possible that American

21. Lorinez, Bela. Die Anwendung des Elektroaspirators in der Frauenheilkunde. Klinische Wochenschrift. 1934; 81: 215-217; Davis, n. 18, p. 136. There are various spellings of Dr. Lorinez's name in the medical literature, including Lorinez, Lorincz and Lorienz. I will use Lorinez as it most frequently encountered.

22. Novak, Emil. A suction-curet apparatus for endometrial biopsy. Journal of the American Medical Association. 1935; 104 (17): 1497-1498; Van der Vlugt et al., n. 2, p. F-26.

23. Davis, n. 17, p. 136;. Hulka, Jaroslav F., ed. Suction evacuation. In: Therapeutic abortion. Chapel Hill-North Carolina: Carolina Population Center; 1968, p. 75. 
physicians were using these devices for abortions without confessing to it in the medical literature.

Employing electrical suction to initiate and complete an abortion did not appear in print until 1958, when Chinese physicians Y. T. Wu, H. C. $\mathrm{Wu}$, and $\mathrm{K}$. T. Tsai presented electrical suction curettage as an innovative therapeutic abortion technique in the same issue of the Chinese Journal of Obstetrics and Gynecology (English language edition) ${ }^{24}$. Their technique involved dilating the cervix using Hegar dilators and a paracervical block, and using a motorized vacuum curette on eight different locations in the uterus. Although this procedure produced successful results, it was time consuming and was not very practical, especially for American abortion providers, many of whom were providing illegal services and needed to do so quickly since the fear of arrest always loomed in the back of their minds.

In 1960, two innovative Russians, E. I. Melks, a physician who had visited China to observe the suction experiments, and L. V. Roze, an engineer, began to examine the vacuum suction procedure as a viable abortion method. Not satisfied with the Chinese equipment available to them, they decided to create their own an apparatus - the «vacuum excochleator»- which used a negative pressure of 0.6 atmospheres, produced by an electrical vacuum pump. In addition to creating their own specialized metal suction curettes, they also crafted detachable mechanical crushers which could be used for the calcified parts of older fetuses (i.e., those greater than twelve weeks of gestation) ${ }^{25}$. For the first time, this innovation proved that the vacuum suction procedure could be used beyond the initial twelve-week limit set by the Chinese physicians. This breakthrough paved the way for the development of other abortion techniques, such as dilation and evacuation (D\&E), which occurred over a decade later.

In 1961, A. V. Zubejev, also a native of Russia, invented a simpler, streamlined, version of the excochleator, which was lighter, portable, and more convenient to use ${ }^{26}$. At the Eleventh All-Union Congress of Gynecology, which was held in Moscow in 1963, Melks reported such great success with Zubejev's machine that vacuum curettage quickly became the abortion

24. Wu, Y. T.; H. C. Wu. Suction in artificial abortion: 300 cases. Chinese Journal of Obstetrics and Gynecology. 1958; 6 (5): 447-449; T'sai, K. T. Application of electric vacuum suction in artificial abortion: 30 Cases. Chinese Journal of Obstetrics and Gynecology. 1958; 6 (5): 445-447.

25. Melks, E. I.; Roze, L. V. Voprosy Akusherstvo Ginekologiia. 1962: 251.

26. Zubejev, A. V. Voprosi Akusersko-Ginekologiceskoj Pomosci. 1962; 1: 25. 
method of choice in the Soviet Union ${ }^{27}$. Obstetricians and gynecologists from all around the world, especially those within the USSR's sphere of influence, began praising the new pregnancy termination technique, many even creating their own versions of Zubejev's apparatus.

Perhaps Zubejev's most successful imitator was Franc Novak, a physician from Yugoslavia who was so impressed with the Russian innovation that he improvised devices based on Zubejev's model and implemented them in his own practice. Soon after Novak's initial experiments with Zubejev's prototype, he, along with engineers from the Institute for Electronics and Automatics in Ljubljana, Yugoslavia (present-day Slovenia), crafted the «VE-2». Although other gynecologists subsequently modified it (they redesigned the rigid metal suction curette which could sometimes cause uterine perforations), the VE-2 remained the basic instrument of choice in Eastern Europe well into the 1970s, and helped stimulate further research on the apparatus and the technique of vacuum abortion ${ }^{28}$.

In 1966, Yugoslavian physician Berislav M. Beric announced that he had redesigned his father's paracervical block technique to be more compatible with vacuum aspiration. The efficacy of the original technique, which was intended to accompany the $\mathrm{D} \& \mathrm{C}$, was never in question; most physicians simply found it too time-consuming because it involved multiple injections of numerous anesthetics, and often took longer than the vacuum aspiration abortion itself. Beric's new paracervical block was essentially a «cocktail» of oxytocin, procaine, papaverine, and atropine, which could be injected, once, into the cervix, prior to abortion ${ }^{29}$. This innovation not only simplified and catalyzed dilation (and therefore the entire abortion process), but also eased the pain of vacuum aspiration and made it a safer experience (oxytocin stimulated uterine contractions, which reduced the patient's chance of hemorrhaging). Beric's cocktail thus increased the feasibility of motorized vacuum suction in both legal, and illegal, outpatient clinical settings, and positioned it as a serious threat to the $\mathrm{D} \& \mathrm{C}$.

27. Melks, E. I. New method of interrupting pregnancy: Vacuum excochleation. Proceedings of the Eleventh All-Union Congress of Gynecology. Moscow; 1963.

28. Novak, Franc. Experience with suction curettage. In: Hall, Robert E., ed. Abortion in a changing world. Vol. 1. New York: Columbia University Press; 1970, p. 75.

29. This «cocktail» is no longer used. Much more common are cervical injections of novocain or xylocaine. Beric, B. M. Vacuum aspiration using paracervical block for legal abortions as an outpatient procedure up to the twelfth week of Pregnancy. Lancet. 1971; 2 (7725): 619621. 


\section{Vacuum aspiration enters American abortion therapeutics}

Franc Novak was one of the first physicians to recognize the technological - and political- power inherent in Beric's «improved» paracervical block technique. In an effort to seize the moment both professionally and commercially, Novak created a film depicting the new anesthetic technique and his own vacuum suction technology, the VE-2. In July 1966, Novak screened the film at an international obstetrics and gynecology conference in Copenhagen, and gave a repeat performance at the 1967 International Planned Parenthood Conference, in Santiago, Chile. Meanwhile, Czech physician and Novak admirer Antonin Cernoch created his own film, «Experience with Intrauterine Suction for Artificial Termination of Early Pregnancy», which he screened at the 1966 Conference on Fertility and Contraception at the State University of New York at Buffalo. The film not only catalyzed Cernoch's rise in the realm of abortion therapeutics, but also created excitement within the American medical community over electric vacuum aspiration ${ }^{30}$. As Peter Forbes, a Los Angeles gynecologist, later recalled, the climate during this period of time was one of both technological «ignorance» and curiosity: «[While] attending a national physicians' meeting in Chicago during the [mid] 1960s, [I] listened in astonishment as a Washington D.C. doctor told of completing an abortion for a Soviet diplomat's wife (...). As the [American] doctor began inserting D\&C instruments to remove the last of the pregnancy, a Russian physician in the operating room asked, 'How come you don't vacuum her?' (...) None of the physicians] had ever heard of this vacuum machine before, and [they] couldn't wait to get [their] hands on one» ${ }^{31}$.

Robert Hall, the famous New York obstetrician/gynecologist and president of the Association for the Study of Abortion (ASA), became one of the first mainstream American physicians to abandon the traditional $D \& C$ in favor of the electrical vacuum aspiration apparatus, and share his experiences with colleagues in the medical community. In 1966, he began using stainless steel curettes of his own design, and a pump from

30. Novak, Franc. Abortion in Europe. Proceedings of the Eight International Conference of the International Planned Parenthood Federation, Santiago, Chile, April 1967. London: International Planned Parenthood Federation; 1967, p. 135-138.

31. Gorney, Cynthia. Articles of Faith: A Frontline History of the Abortion Wars. New York: Simon and Schuster; 1998, p. 197. 
the Gomco Surgical Manufacturing Corporation of Buffalo, New York, to perform dozens of early motorized vacuum suction abortions on both his hospital and clinic patients. In almost all of his cases, he used some sort of anesthesia (either general, or a local paracervical block), as well as Hegar dilators to expand the cervix. However, in emergencies, he still relied on the $\mathrm{D} \& \mathrm{C}$ to make sure that the uterus was completely empty. Nevertheless, Hall immediately recognized - and to a certain extent was alarmed by - both the technological and political implications of this new abortion technique. It had the potential to transform therapeutic abortion from a surgical procedure, which was usually regulated and performed by hospital physicians, to a ten minute «in and out» clinical treatment that, at least in theory, could be managed competently by anybody with a vacuum apparatus and a «working knowledge of basic gynecology» ${ }^{32}$. Despite his professional concerns, Hall recommended the technology, and called for the writing of new texts, and the production of better films, which would educate American gynecologists about electrical vacuum aspiration abortion.

One of the products of this effort was the 1966 film «Vacuum Aspiration Termination of Pregnancy», which depicted the work of Dorothea Kerslake, a British obstetrician/gynecologist from the University of Newcastle-UponTyne. The president of the Lalor Foundation, Lalor Burdick, believed so firmly in the new technology that he helped distribute Kerslake's film to physicians, hospitals and medical schools in the United States, underwrote the cost of hospital vacuum suction machines well into the 1970s, and even visited Franc Novak's clinic in Yugoslavia to observe his vacuum aspiration techniques first hand ${ }^{33}$. The efforts of these individuals were facilitated by the publication of two important articles in the July 1967 issue of Obstetrics and Gynecology. The first article focused on the vacuum aspiration experiences of Czechoslovakian physician M. Vojta. However, it was the second article, «Abortion Induced by Means of the Uterine Aspirator», written by Dorothea Kerslake and Don Casey which caught most physicians' attention. In the article, Kerslake and Casey openly stated what Hall had been considering for over a year: that vacuum suction, using electrical pumps,

32. Hall, Robert. Induced abortion in New York City. American Journal of Obstetrics and Gynecology. 1971; 110 (5): 601-611; Gorney, n. 31, p. 198.

33. Joffe, Carole. Doctors of Conscience: The Struggle to Provide Abortion Before and After Roe v. Wade. Boston: Beacon Press; 1995, p. 44; Hulka, n. 23, p. 76. 
suction curettes, and paracervical anesthesia to dull the pain associated with cervical dilation, should replace the $D \& C^{34}$.

Although by the late 1960s, a number of innovative American physicians (most of whom were politically active in the abortion movement) were already familiar with the electric vacuum suction apparatus, the ASA's November 1968 Hot Springs Conference is generally credited with introducing most American physicians to the «new» technology for the very first time. Guttmacher and Hall predicted that abortion would become legal in the United States, and believed that American physicians needed to learn how to provide vacuum suction abortions as soon as possible. To accomplish this goal, they, along with Lalor Burdick, persuaded Franc Novak to speak at the conference and share his vacuum suction experience with American physicians ${ }^{35}$. In the middle of his mostly technical report, Novak delivered a remarkably elegant, and convincing, argument for the adoption of the innovative machine: «While a D\&C gives the impression of a rude artisan's work, an abortion performed with suction gives the impression of a simple mechanical procedure». However, Novak's eloquence came with a stern, and later, significant, warning: «This operation should only be done by specialized gynecologists after additional training in this technique (...). It should only be done in good hospitals with anesthesia and additional care after the operation» ${ }^{36}$. Thus he not only reinforced the notion that abortion (even when induced through simpler techniques) should be in the hands of fully-qualified professional physicians, but that specialists - perhaps even sub-specialists trained in abortion technology- should be the individuals terminating pregnancies.

\section{American physicians' reactions to vacuum aspiration}

Despite efforts to popularize the technique, American physicians' initial reactions to the new technology were mixed. Some physicians were reluctant to try it for both medical and political reasons. Feminists, such as

34. Vojta, M. A critical view of vacuum aspiration: A new method for the termination of pregnancy. Obstetrics and Gynecology. 1967; 30 (1): 28-34; Kerslake, D; Casey, D. Vacuum aspiration. Obstetrics and Gynecology. 1967; 30 (1): 35-45.

35. Hulka, n. 23, p. 76; Joffe, n. 33, p. 44.

36. Novak, n. 30, p. 77, 81. 
Patricia Maginnis (who was also the president of the Society for Humane Abortion), were recommending the apparatus long before most American doctors had even heard of the technique. Physicians who were not involved in the abortion rights movement often regarded activist women with contempt and suspicion, and did not want to associate themselves, even technologically, with women who sought to destabilize the medical hierarchy by taking reproduction into their own hands. Other physicians, particularly those over fifty, who in medical school were told that the $\mathrm{D} \& \mathrm{C}$ was «the answer to all female complaints», were reluctant to learn a new technique so far along in their careers. Meanwhile, those working in secrecy either could not afford the machinery, or did not want to take the risk of working with equipment that could not be easily moved should a police raid occur ${ }^{37}$.

Some physicians derived their negative opinions about electrical vacuum aspiration from personal experience. Minnesota physician Jane Hodgson disparaged the new apparatus: «Our first equipment was crude, noisy and even dangerous. The vacuum pressure was not measured. Some of the earliest equipment simply utilized the [powerful] wall suction in the operating room, which was designed for use with fluid-draining equipment during surgery» ${ }^{38}$. As New York obstetrician/gynecologist William Rashbaum recalled, «the suction machine was a pump attached to a Dixie cup, with the top held on with rubber bands (...) there were a number of deaths from the suction machine. If connected incorrectly the machine would blow instead of suction, causing some patients to die of air embolus» ${ }^{39}$. The technological skepticism of these physicians was understandable. In the late 1960s, there still existed two technical drawbacks to the apparatus: the unpredictable suction, and the rigid metal cannulas whose use, like the $\mathrm{D} \& \mathrm{C}$, required a fair amount of skill on the part of the operator, since any mistake could result in uterine perforation, infection, and possibly death ${ }^{40}$.

On the other hand, there were many physicians who were excited about the new technology. It drew enormous praise from physicians practicing in

37. Benderly, Beryl L. Thinking About Abortion. Garden City, NY: The Dial Press; 1984, p. 90-91.

38. Hodgson, n. 3, p. 235.

39. Rashbaum, William K. In his own words. Physicians for Reproductive Choice and Health. [cited 19 Mar 2008]; p. 10-11. Available at: http://www.prch.org/assets/16_inhisownwords

40. Beck, Mildred B. et al. Abortion: A national public and mental health problem — past, present and proposed research. American Journal of Public Health. 1969; 59 (12): 2131-2143. 
large urban centers on the East and West Coasts, such as Barry Messinger and Daniel Fieldstone (pseudonym). Fieldstone completed his residency in obstetrics and gynecology (and presumably abortion training) at Mount Sinai Hospital, under the tutelage of Alan Guttmacher. He spent most of the 1950s and 1960s performing illegal abortions in New York, and was persuaded by his mentor to attend the 1968 Hot Springs Conference. The conference held both personal and professional significance for Fieldstone because it made him feel part of a legitimate community of «extralegal» abortion providers who were technological innovators in their own right. According to Fieldstone, «That meeting (...) really changed everything. It brought together (...) what was known then about techniques.' Like many of the physicians at the conference whose hospital-based abortion experience was limited to the $\mathrm{D} \& \mathrm{C}$ method, Fieldstone [instantly recognized the power of the] vacuum suction machine, which [seemed to be] a far safer method of early abortion. The suction was an eye opener, it was such a superior technique -it shocked us» ${ }^{41}$.

Messinger, a professor of obstetrics and gynecology at the University of California at San Francisco (UCSF) medical center, was also «very impressed with the ease and safety of the suction method». However, as an Israeli colleague reminded him, «you can do abortion this way...but you need to find a source of vacuum pumps» ${ }^{42}$. Because the technology was still in its early stages in the United States, the machinery was very difficult to obtain. While Hall and a few other early users of the electrical vacuum suction apparatus were able to either create their own implements, reconfigure devices purchased from American manufacturers to fit their needs, or import them from overseas from companies such as Rocket of London, Messinger knew that in order for the technology to replace the $\mathrm{D} \& \mathrm{C}$ in the United States, physicians would not only have to be convinced of its merits, but would also have to be able to purchase the equipment easily, and without great hassle or expense.

41. Joffe, n. 33, p. 76.

42. Joffe, n. 33, p. 131. 


\section{Technological innovation, legalization, and the rise of vacuum suction abortion}

A number of obstetrics/gynecology faculty members at UCSF decided that creating an American electrical vacuum aspirator, which could then be mass-produced and mass-marketed to US physicians, was the most effective means of introducing the pregnancy termination technology to the medical profession. They asked an acquaintance, medical engineer and entrepreneur William Murr, to construct the prototype. After a trip to Tokyo to examine the equipment being used by Japanese abortion providers, Murr devised «a toaster sized, mechanical vacuum pump, improvised from a paint sprayer that was set to operate in reverse». The pump was outfitted with two glass collection bottles, and cannulas and tubing made of clear plastic (the plastic tubing was originally Kerslake's idea). Murr believed that this design - especially the plastic cannulas and tubing - would reduce uterine perforation, and make vacuum suction abortions safer by allowing the physician to observe the procedure as it happened. However, as UCSF obstetrician/gynecologist Alan Margolis observed, there were drawbacks to Murr's apparatus: «the cannulas, the open-ended tubes that entered the uterus, [were] so rigid and wide that he was afraid that if a doctor did perforate the uterine wall, the vacuum would immediately begin sucking up bowel». Murr readjusted the design, and with the financial backing of his newly-formed «Berkeley Bioengineering Company», released the first advertising brochure for the «VC-1» vacuum aspiration unit, which came with his trademarked narrow, plastic, rigid cannula, the «vacurette». The VC-1 began «selling, one at a time. [Murr] sent one machine to Denver, another to Philadelphia» ${ }^{43}$. Dr. George I. Solish, from the King's County Hospital in Brooklyn, New York also became an early supporter of the Berkeley apparatus ${ }^{44}$. Alan Margolis purchased a Berkeley aspirator for his UCSF Medical Center clinic, and began taking notes on the «safety and efficiency» of the abortion technology. According to Margolis, and Crosby Eaton, an

\footnotetext{
43. Gorney, n. 31, p. 198-199.

44. Solish, George I. Aspiration curette in the treatment of incomplete abortion. In: Sobrero, Aquiles J., ed. Advances in planned parenthood, vol. V. Amsterdam: Excerpta Medica Foundation; 1970, p. 213-218.
} 
obstetrician/gynecologist from the University of Michigan, using the VC-1 was «a lot easier (...) [and] obviously a much safer thing to do» ${ }^{45}$.

When New York State's abortion laws were liberalized in 1970, obstetrician/gynecologist Dr. Bernard Nathanson, who had vowed to make abortion safe and legal, bought a Berkeley apparatus for his clinic, the Center for Reproductive and Sexual Health, which, at the time, was the largest legal abortion clinic in the western world ${ }^{46}$. Nathanson maintained that the Berkeley suction unit was inexpensive, and much cleaner, more reliable, and far more suitable for the new outpatient setting than the $\mathrm{D} \& \mathrm{C}$. To prove it, his clinic performed hundreds of abortions with the apparatus ${ }^{47}$. As the success of Murr's machine spread, other aspirator manufacturers began to appear around the country (e.g., the Battelle Corporation of Seattle, C. M. Sorensen and Co. of Long Island City, New York, and Air-Shields, Inc. of Hatboro, Pennsylvania), and the technology entered mainstream medicine.

\section{The Karman cannula and the politics of abortion technology}

The entry of the electrical vacuum aspiration machine into the medical mainstream was clearly facilitated by the fact that abortion was being decriminalized on a state-by-state basis just as physicians such as Margolis and Nathanson were discovering the apparatus. However, it was also catalyzed by a second technological breakthrough: the Karman cannula. While Murr's transparent plastic cannulas were undoubtedly an improvement over Kerslake's solid metal cannulas, they still were therapeutically cumbersome: they required sterilization between each use, and could only be used with Murr's vacuum aspiration unit. Moreover, because of the width of Murr's cannula, physicians still had to dilate the cervix (which usually required local anesthesia), and the rigidity of the cannula continued to posed the risk (albeit reduced) of uterine perforation. The thin, flexible, disposable, inexpensive plastic Karman cannula, on the other hand, almost eliminated the perforation, dilation, and anesthesia associated with conventional va-

\footnotetext{
45. Gorney, n. 31, p. 199; Eaton, Crosby. Uterine aspiration for evacuation of the pregnant uterus. Journal of the American Medical Association. 1969; 207 (1): 1887-1889.

46. Nathanson, Bernard. Deeper into abortion. New England Journal of Medicine. 1974; 291 (22): $1189-1190$.

47. Nathanson, Bernard. Suction curettage in early abortion. Modern Treatment. 1971: 64-71.
} 
cuum aspiration. In addition, because it could be used with any aspiration apparatus and then simply discarded, the Karman cannula also reduced sterilization costs and the risk of infection and cross-contamination between patients ${ }^{48}$.

This new cannula was the invention of Harvey Karman, one of the most important - and controversial- figures in the history of twentiethcentury abortion technology ${ }^{49}$. Karman is historically significant not only for his technological contributions (namely the Karman cannula, which led to the widespread acceptance of suction abortion, and to this day, remains the vacuum aspiration attachment of choice), but also for his political and professional confrontations with American physicians.

Karman first surfaced on the abortion scene in the 1950s, when he began performing illegal lay abortions in California. During one of his many prison stays in the early 1960s, he created the "Karman cannula», a device that, he believed, would eliminate the triple threat of electrical vacuum aspiration: uterine perforation, dilation and anesthetization of the cervix, and blockage of the cannula during suction. Following his release from prison, Karman immediately sought to establish connections within the medical community: «I got some of the doctors [I knew] to give me the [fetal] tissue they had removed with the curette, and I tried aspirating it through different diameters to see just how big a diameter was required» ${ }^{50}$. Once Karman realized that it was possible to aspirate a twelveweek-old fetus (the upper gestational limit of vacuum aspiration) through a very narrow tube without cervical dilation, anesthesia, analgesics, or even antibiotics, he knew that the next step was to rethink the design and composition of the cannula. He settled on a transparent, flexible, tubular polyethylene suction curette that, unlike the other hollowed-out, rigid metal and plastic curettes that had preceded it (such as those designed by Rock, Novak, Kerslake, Murr and Rocket of London), was bendable. This made abortions safer by reducing the likelihood of uterine perforation, and

48. Goldsmith, Sadja; Margolis, Alan. Aspiration abortion without cervical dilation. American Journal of Obstetrics and Gynecology. 1971; 110 (4): 580-582.

49. Tunc, Tanfer Emin. Harvey Karman and the super coil fiasco: A forgotten episode in the history of abortion technology. European Journal of Contraception and Reproductive Health Care. 2008; 13 (1): 4-8.

50. Interview with controversial Harvey Karman: A pioneer in modern birth control. Environmental Quality Monthly. 1973: 48; Dor, Jan Ben. Karman as hero: Abortion innovator exhibits sexism. Herself. 1973; 2 (5): 1. 
increasing the ease with which operators could manipulate the cannula. Its transparency provided more visual control, and its two elongated, lateral apertures, which were located at the tip of the cannula, remained open and did not fill with fetal matter ${ }^{51}$.

Karman knew he had a very important technological breakthrough in his hands, but did not know how to publicize it. He began by performing clinical tests with a rather skeptical doctor: «I persuaded the doctor to use the cannula as a probe to measure the position and depth of the uterus while I was applying vacuum pressure. Then he proceeded to perform a conventional D\&C and was quite surprised to find there was no tissue left». At this point Karman realized the true power of his cannula - it rendered obsolete the over forty instruments used during a typical D\&C - and started spreading the word with help from graduate students from his alma mater UCLA, where he had earned a Masters Degree in Theatre Arts. When that approach did not work, he created his own television commercial, advertising free Karman cannula vacuum aspiration abortions. In 1969 he was arrested yet again, but this time, he became an overnight celebrity ${ }^{52}$.

The controversy surrounding Karman began when he was released from prison and, despite his lack of medical credentials, started referring to himself as «Dr.» Karman ${ }^{53}$. However, this did not deter some members of the mainstream American medical community from embracing Karman and his cannula. Karman gained the support of UCSF obstetrics and gynecology faculty members, including Alan Margolis and Sadja Goldsmith, both of whom were well-known figures in mainstream medicine, especially in abortion circles ${ }^{54}$. The physicians were enthralled by Karman's cannula, and like its innovator, believed that it had the potential to revolutionize abortion therapeutics. Margolis and Goldsmith immediately began promoting the cannula, even co-authoring an article about the apparatus for the American Journal of Obstetrics and Gynecology ${ }^{55}$.

\footnotetext{
51. Wohl, Lisa. The Harvey Karman controversy. Ms. Sept 1975: 61-63.

52. Dor, n. 50, p. 1; Two minute abortion is here — are we ready? Medical World News. 12 May 1972: 15-17; Wohl, n. 51, p. 61-63.

53. Hirsch, Jeanne. Harvey Karman. The Monthly Extract. 1973; 2 (4): 4; Dor, Jan Ben. Harvey Karman: Another vacuum cleaner salesman? Herself. 1973; 2: 9; Nathanson, Bernard. Aborting America. Garden City, New York: Doubleday; 1979, p. 91.

54. Joffe, n. 33, p. 131.

55. Goldsmith, Sadja; Margolis, Alan. Aspiration abortion without cervical dilation. American Journal of Obstetrics and Gynecology. 1971; 110 (4): 580-582.
} 
Initially, not all physicians were as excited about Karman, or his cannula, as Margolis and Goldsmith. One Ann Arbor, Michigan obstetrician/ gynecologist was particularly troubled by Karman's checkered past as an illegal abortion provider. However, he reluctantly decided «to let sleeping dogs lie [and focus on] the fact that he [exhibited] a long standing concern with students [and] with improving abortion». Abortion-providing physician-activist Bernard Nathanson approved of Karman's hostility towards the conservative medical establishment, but was troubled by his attitude, which for Nathanson personified the worst aspects of the illegal, nonphysician abortion provider. The fact that Karman directly challenged the entire medical profession by encouraging paramedical professionals, who were not doctors, to perform vacuum suction abortions, and relished being called «Dr.» Karman, even though he did not possess a medical degree, only served to reinforce this notion ${ }^{56}$. Nathanson was also very critical of Karman's therapeutic claims. Nathanson believed that it was possible to perforate the uterus with the cannula, which, in his opinion, was merely a hollow flexible tube that resembled a bent «straw». He was convinced that Karman's claims were «inaccurate and irresponsible»: the cannula was too narrow to allow fetal material to pass through it as its creator claimed, and too wide to eliminate dilation and anesthesia, especially in women who were pregnant for the first time ${ }^{57}$.

\section{Conclusion: The Karman revolution}

Despite the controversy that surrounded his methods and qualificatio$\mathrm{ns}$, in the end, Karman was hailed a medical innovator. He even earned the respect of abortion researcher Dr. Christopher Tietze who declared Karman's electrical vacuum suction abortion technique a «revelation and a revolution» ${ }^{58}$. Thus for many, electrical vacuum aspiration using the Karman cannula was a technological miracle that fit perfectly into the social, political, medical, economic and legal contexts of abortion during the early

\footnotetext{
56. Dor, n. 53, p. 9; Nathanson, n. 53, p. 85-92; Karman, Harvey. The paramedic abortionist. Clinical Obstetrics and Gynecology. 1972; 15 (2): 379-387.

57. Nathanson, n. 53, p. 86-87.

58. Hirsch, n. 53, p. 4; Wohl, n. 51, p. 63.
} 
1970s. Abortion was gradually decriminalizing in the United States, and the outpatient abortion clinic system was rapidly establishing itself in major urban centers to meet the increasing demand for pregnancy termination. As the rigid hospital therapeutic abortion system crumbled, physicians became inspired to perform abortions openly and freely ${ }^{59}$. However, the metal cannulas, vacuum pumps, dilators, curettes, specula, anesthetics and painkilling drugs that had been used during the 1960s were labor and cost intensive to obtain and maintain (when abortion was legalized in New York in 1970, a committee estimated that each clinic would require $\$ 250,000$ worth of abortion equipment in order to function). Hospitals could afford such expenses; these burgeoning abortion clinics could not. Consequently, a different technological system was called for -one which relied on disposable equipment, and did not require expensive sterilization and costly pharmaceuticals. Electrical vacuum aspiration using the Karman cannula, disposable curettes, specula, and surgical linens, provided this revolutionary system ${ }^{60}$.

This new technological system not only proved that pregnancy termination could be fast, safe, cheap, efficient, clean and uncomplicated, but also created a market which helped maintain the abortion industry. With the disposability of abortion equipment came the cycle of production, purchase, and consumption. This kept the corporations that produced this specific type of medical equipment - such as Battelle, Rocket, and Berkeley Bioengineering - profitable. However, this system, as lucrative and competitive as it was, also provided the physicians who ran the abortion clinics with the opportunity to create their own identity - one which was not only technologically and professionally distinct (it could not be associated with the older generation of physicians who supported the $D \& C$, and the medically and politically flawed therapeutic abortion system), but one that

59. Branch, Benjamin. Outpatient termination of pregnancy. In: Potts, Malcolm, ed. New Concepts in Contraception. Baltimore: University Park Press; 1972, p. 175-199; Alan Guttmacher Institute, Abortion 1976-1977: Needs and services in the United States. New York: Alan Guttmacher Institute; 1979, p. 44.

60. Abortion in New York. Time. 7 Sept 1970: 48; Tyler, Carl. The logistics of abortion services in the absence of restrictive criminal legislation in the United States. American Journal of Public Health. 1971; 61: 497-499; Joffe, n. 33, p. 141. 
also meshed perfectly with the new consumer-oriented medicine that was emerging during the early 1970 s $^{61}$.

Gradually, many abortion providers began to agree that the Karman cannula was the best vacuum attachment on the market. Some physicians, such as Richard M. Soderstrom, even tried to persuade colleagues to discontinue their use of Karman's competitors, which included the Swedishdesigned Vabra aspirator (manufactured by Cooper Laboratories Inc., of Wayne, New Jersey), the Berkeley vacurette, and the Novak curette. In his opinion, all of these «outdated models» had «insufficient suction ports to guarantee [the] satisfactory evacuation of [the] uterine contents», and could actually «shear the endometrial lining when used in a rotational manner» ${ }^{62}$. Other physicians went as far as arranging entire conferences around Karman's cannula, which was attracting more and more users. Probably the most significant conference of this genre was the Symposium on Clinic and Office Abortion Procedures, held in Madison, Wisconsin, on October 23, 1971. Organized by Dr. Thomas M. Hart and the SHA, and attended by forty two physicians, the conference essentially served as a forum where early participants in vacuum aspiration, such as Goldsmith, Margolis, and Karman associate Dr. John Gwynne, could discuss their clinical experiences with the new apparatus.

The symposium's focus was on the impact that the Karman cannula was making in the realm of abortion technology, and was essentially one congratulatory speech after another. While most presentations attempted to incorporate the clinical applications of the apparatus, others were blatantly designed to praise Karman, who was in attendance. Washington State abortion provider, Dr. A. Frans Koome, was probably the most enthusiastic Karman supporter, thanking the innovator «for the cannula he designed: a lot of women owe a great deal to this little thing and to the brain that developed it». The symposium proceeded without incident until a heated debate erupted between Gwynne and Berkeley Bioengineering representative John Lang. Gwynne began the discussion by criticizing the Berkeley apparatus as being impractical, expensive, and dangerous (i.e., its rigid vacurette could

61. Wassertheil-Smoller, Sylvia M. et al. New York State obstetricians and the new abortion laws: Physician experience with abortion techniques. American Journal of Obstetrics and Gynecology. 1972; 113: 979-986.

62. Soderstrom, R. M. Menstrual regulation technology. In: Zatuchni, Gerald, ed. Pregnancy Termination. Cambridge, MA: Harper and Row Publishers; 1978, p. 62. 
perforate the uterus, and cause cervical trauma). The debate escalated when the physician began a personal attack on Lang: «I want you to know that I'm going to be one of your competitors (...) I've been forced to build my own machines. The second one was easy and the third was easier. Is your price going down a little now? (applause)» ${ }^{63}$.

Gwynne's comment was particularly significant because it articulated many of his colleagues' personal and political experiences with abortion technology. Discontent with the $\mathrm{D} \& \mathrm{C}$, and enthusiastic about its alternative, vacuum aspiration, this generation of physicians dared to cross therapeutic boundaries by adopting a new procedure, only to find it as medically, economically, and commercially flawed as its predecessor. Using their intuition and entrepreneurial skills, they reconfigured, and in some cases (such as Gwynne's), even created generic pregnancy termination technologies to complement their clinical situations. In doing so, they illustrated that technology is both reactive and interactive: it is not merely a product of technological innovators, but also the result of its social, political, economic and legal contexts. The cycle of competition and innovation in which they engaged ultimately resulted in safer, cheaper, and more efficient abortion technologies. These technologies not only benefited the physicians themselves (by driving out challengers, improving therapeutic outcomes, and increasing their authority over the procedure), but also the women they were treating, who could now obtain abortions without many of the medical (and eventually legal) concerns that had plagued pregnancy termination in the past.

By the end of the conference, it was clear that the reign of the D\&C had finally come to an end. Clinical research studies conducted by respected organizations such as Tietze's Joint Program for the Study of Abortion, and the National Institutes of Health, were calling for the adoption of electrical vacuum suction abortion, using the Karman cannula, as «standard medical practice» ${ }^{64}$. When Nathanson, Beric, and the medical director of the

63. Hart, Thomas, ed. Abortion in the Clinic and Office Setting. Long Beach, CA: Society for Humane Abortion; 1972, p. 20-21, 27.

64. Tietze, C.; Lewit, S. Joint program for the study of abortion: Early medical complications of legal abortion. Studies in Family Planning. 1972; 3 (6): 97-124; Novak, F. Comparison of the medical effects of induced abortion by two methods: Curettage and vacuum aspiration. Bethesda: National Institutes of Health, Center for Population Research. 1971; Margolis, A.J.; Overstreet, E.W. Legal abortion without hospitalization. Obstetrics and Gynecology. 1970; 36 (3): 479-481. 
second largest abortion clinic in the United States, Benjamin Branch, who managed Preterm in Washington, D.C., declared the Karman cannula part of «the procedure of choice for early [pregnancy] termination», no one could legitimately deny that electrical vacuum aspiration, the cannula, and its controversial innovator, had become part of medical history ${ }^{65}$.

65. Nathanson, Bernard. Ambulatory abortion: Experience with 26,000 cases. New England Journal of Medicine. 1972; 286: 403-415; Beric, B. M. The Karman catheter: A preliminary instrument for the termination of pregnancies up to twelve weeks of gestation. American Journal of Obstetrics and Gynecology. 1972; 114 (2): 273-275; Harting, Donald. Abortion techniques and services. American Journal of Public Health. 1971; 61 (10): 2085-2105. 